\title{
Supercritical Fluid Technologies to Fabricate Proliposomes
}

\author{
James R. Falconer ${ }^{1,2}$, Darren Svirskis ${ }^{2}$, Ali A. Adil ${ }^{2}, Z_{\text {Zimei Wu }}^{2}$ \\ ${ }^{1}$ School of Pharmacy, Pharmacy Australia Centre of Excellence, University of Queensland, Brisbane, QLD 4102, \\ Australia; ${ }^{2}$ School of Pharmacy, Faculty of Medical and Health Sciences, University of Auckland, Auckland 1010, New \\ Zealand
}

Received, September 20, 2015; Revised, November 1, 2015; Accepted, November 10, 2015; Published, November 10, 2015.

\begin{abstract}
Proliposomes are stable drug carrier systems designed to form liposomes upon addition of an aqueous phase. In this review, current trends in the use of supercritical fluid (SCF) technologies to prepare proliposomes are discussed. SCF methods are used in pharmaceutical research and industry to address limitations associated with conventional methods of pro/liposome fabrication. The SCF solvent methods of proliposome preparation are eco-friendly (known as green technology) and, along with the SCF anti-solvent methods, could be advantageous over conventional methods; enabling better design of particle morphology (size and shape). The major hurdles of SCF methods include poor scalability to industrial manufacturing which may result in variable particle characteristics. In the case of SCF anti-solvent methods, another hurdle is the reliance on organic solvents. However, the amount of solvent required is typically less than that used by the conventional methods. Another hurdle is that most of the SCF methods used have complicated manufacturing processes, although once the setup has been completed, SCF technologies offer a single-step process in the preparation of proliposomes compared to the multiple steps required by many other methods. Furthermore, there is limited research into how proliposomes will be converted into liposomes for the end-user, and how such a product can be prepared reproducibly in terms of vesicle size and drug loading. These hurdles must be overcome and with more research, SCF methods, especially where the SCF acts as a solvent, have the potential to offer a strong alternative to the conventional methods to prepare proliposomes.
\end{abstract}

This article is open to POST-PUBLICATION REVIEW. Registered readers (see "For Readers") may comment by clicking on ABSTRACT on the issue's contents page.

\section{INTRODUCTION}

Liposomes are spherical nano/micro-sized spherical vesicles composed of an aqueous core enclosed by one or more phospholipid layers. Liposomes are similar in structure to cells in the body, and are considered to be non-toxic, biodegradable, and biocompatible. Since the discovery of liposomes by Bangham, et al., in the mid-1960 (1) a substantial research field has spawned with liposomes being developed as novel drug delivery systems (DDS). Proliposomes are fine granules composed of bioactive and phospholipids, and upon hydration with aqueous phase prior to administration, they are converted into liposomes. This solid state formulation offers the advantage of being more physically and chemically stable on storage than liposomes $(2,3)$. Proliposomes have been used to form DDS for the anti-cancer agents such as doxorubicin HCL (Myocet by Zeneus Pharma, Oxford, UK) $(4,5)$ and for fungal infections such as amphotericin B (AmBisome by Gilead Sciences, Foster City, California, USA) (6). Since being introduced by Payne, et al. in the 1980s (3), many methods have been developed to make proliposomes with pharmaceutical application. The final product, however, is that to form a liposome from proliposome solid materials, hydration or reconstitution is required to achieve this transformation. There are a several ways to form liposomes from proliposomes, such as using an aqueous buffer (7) with stirring or heating, as shown in Fig $1(8,9)$. The commercial products come with vials of proliposomes and buffer, and for the anti-fungal product, the excipients include sodium $<0.5 \mathrm{mmol} / \mathrm{vial}$ and sucrose $900 \mathrm{mg} / \mathrm{vial}$. A simple reconstitution method prior to administration is required so that patients can readily be given their medicines by health practitioners such as doctors and nurses, or if possible where a patient themselves could prepare liposomes. Perhaps the latter scenario would be only possible if the route of administration did not involve the use of parenteral application e.g. an oral formulation.

\footnotetext{
Corresponding Authors: Dr. Falconer, School of Pharmacy, University of Queensland, Pharmacy Australia Centre of Excellence, Level 4, 20 Cornwall Street, Woolloongabba, Queensland 4102, Australia. E-mail: j.falconer@uq.edu.au. Dr. Wu, School of Pharmacy, Faculty of Medical and Health Sciences, University of Auckland, Private Bag, Auckland 1010, New Zealand. E-mail: z.wu@auckland.ac.nz
} 


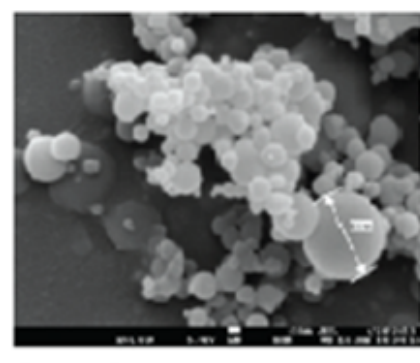

\section{$\operatorname{Ref}[8]$}

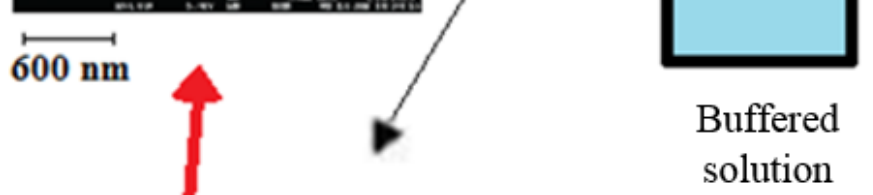

Heating $30-40^{\circ} \mathrm{C}$
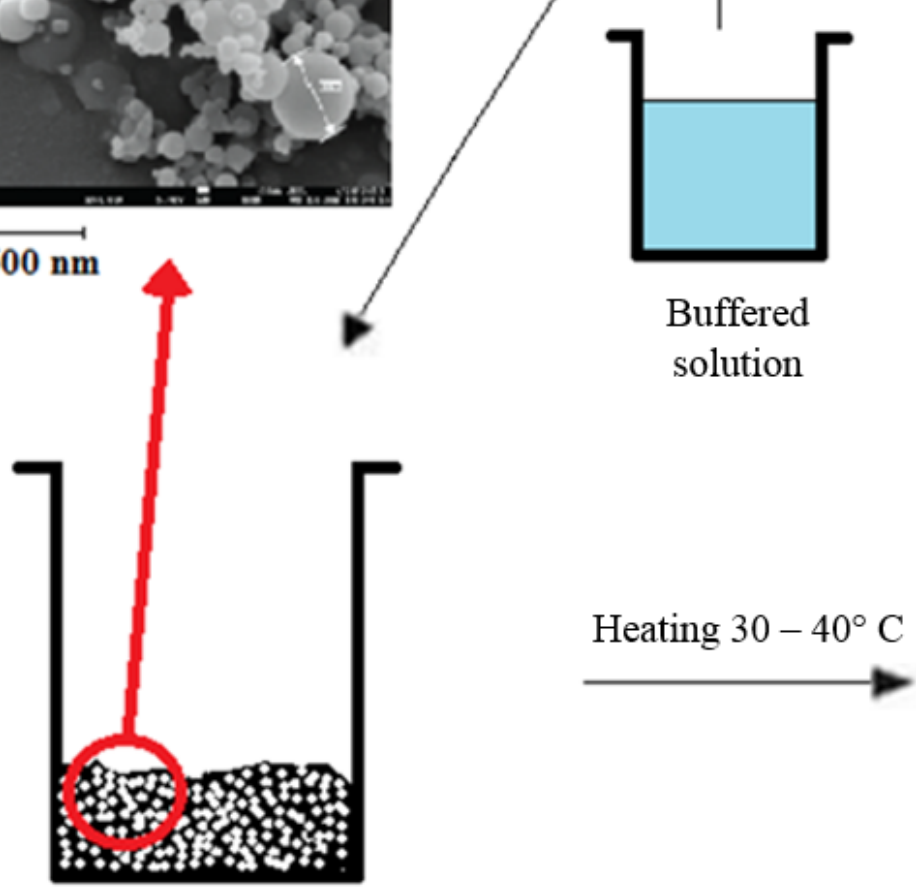

\section{Solid proliposome containing drug}

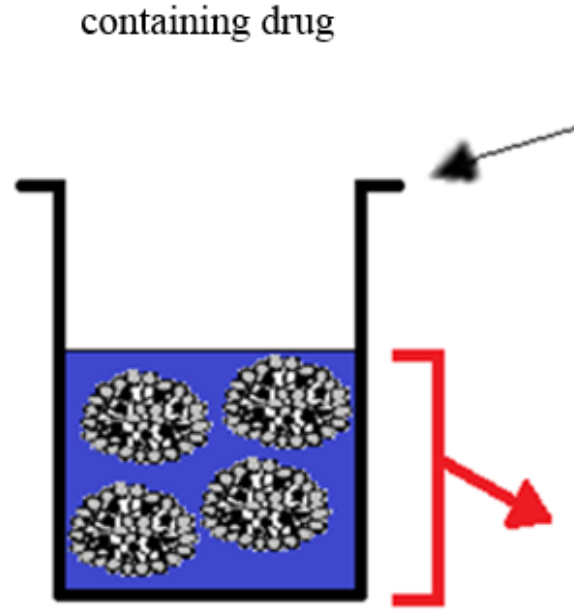

Drug loaded liposome

- = lipophilic drug molecule he lipids

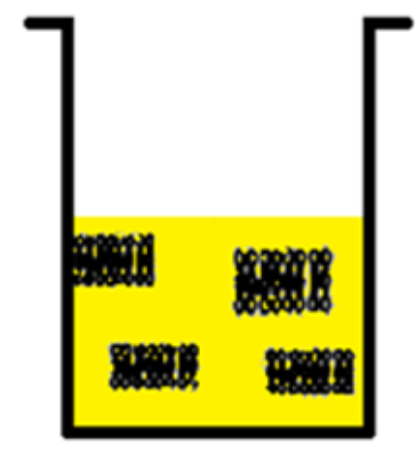

Hydrated phosphatidylcholine

\section{Heating to reduce aqueous phase}

Ref [9]
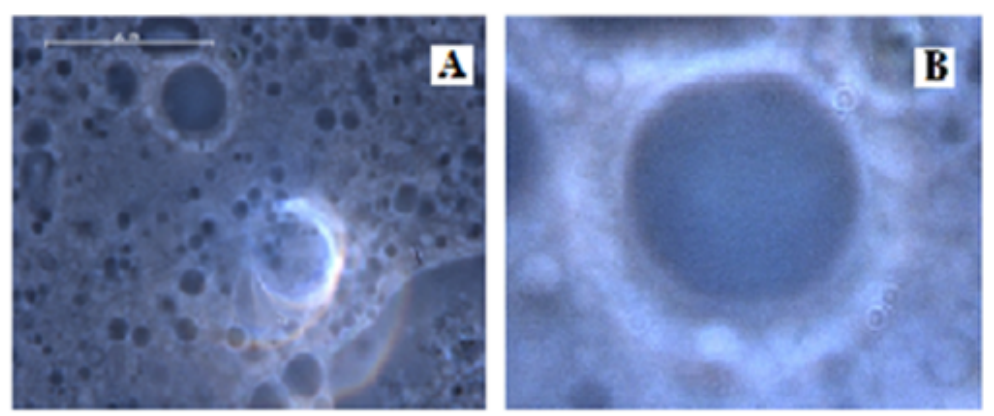

$20 \mu \mathrm{m}$

Figure 1. Possible steps to form liposomes from solid proliposomes. SCF-EPCS solid proliposomes are shown in the SEM image from Reference (8). In the liposome, the possible locations for a lipophilic drug are among the alkyl tails of the phospholipids. Rehydrated liposomes prepared using a SCF method are shown in the microscopic images from Reference (9). Reference (9)B, enlargement of a liposome (8, 9). EPCS, phosphatidylcholine from egg lecithin; SEM, scanning electron microscopy. Copyright (2015) Reference (8) reproduced with permission from Int J Nanomed 2014:9(1) Pages 5079 - 5091 [Dove Medical Press] and Reference (9) reproduced with permission from J of Supercritical Fluids 2012:72 Pages 125 - 133 [Elsevier]. 
The special characteristics of liposomes make them a highly versatile DDS as one or more active pharmaceutical ingredients (APIs) can be loaded into one system, with hydrophilic APIs encapsulated in the aqueous core and lipophilic APIs residing within the lipid bi-layer (10). As DDS, liposomes can facilitate the delivery of drugs via different routes of administration, such as parenteral, dermal and transdermal, and pulmonary routes. In each case, the liposomal carrier systems play different roles such as solubliser, skin penetration enhancer, and sustained release system (11). Most importantly, liposomes have the potential to confer the drug tumour-targeting property, enhancing the therapeutic outcome of anti-cancer drugs (12). Liposome encapsulation prevents the entrapped cytotoxic drugs from passive diffusion into non-targeted tissues leading to side effects (13). Selective tumour localization is further achieved through the enhanced permeability and retention (EPR) effect by exploiting the leaky vasculatures of the tumours (14). In this case liposomes must meet certain criteria, the least of which are; an effective size range (50 to $200 \mathrm{~nm}$ ) (15), a relatively long plasma residence time (half-life $>6 \mathrm{~h}$ ) to allow accumulation at the tumour site following extravasation through leaky tumour vasculature $(16,17)$.

Designing liposomal DDSs is a challenging task with vesicle size, size distribution, morphology, and membrane composition all influencing performance. Furthermore, issues with the physical and chemical stability of liposomes can limit their use (2). Liposomes themselves can be physically unstable due to spontaneous and irreversible aggregation and fusion, which can be associated with a loss of captured active molecules. Chemical instabilities in constituent phospholipids due to hydrolysis and oxidation altering the functions of the drug delivery vehicle (18). In addition, the high cost of materials and typically tedious manufacturing processes which require multiple steps, which are time consuming and labour intensive and the use of organic solvents has limited development and manufacturing by the pharmaceutical industry $(19,20)$. Despite these drawbacks, liposomes remain a strong platform for future DDSs due to their versatility and proven efficacy (2). One way to address the stability drawbacks of liposomes is in the preparation of aqueous free proliposomes, or solid pre-liposomes, which can be simply converted to liposomes when required, prior to administration. There are several conventional methods reported to produce proliposomes, some of them are practically similar to the methods used to make liposomes such as the Bangham method followed by a solid-state preparation step, i.e. dehydration, see Table 1.

As shown in Table 1, the conventional proliposome preparation methods usually require a substantial use of organic solvents. This shortcoming has two main implications, firstly the organic residue within the final product must be within strict levels set by regulators (good manufacturing practice, GMP), and secondly, the waste solvents must be discarded in such a way that the environmental impact is minimal complying with the further governmental regulations (37). The US Food and Drug Administration (FDA) and European Union (EU) have well established regulations on the use of organic solvents. In 2007, the EU implemented the legislation REACH (Registration, Evaluation, Authorisation and Restriction of Chemicals) with the intention to promote the use of alternative methods and chemicals in order to protect human health and the environment (37). An additional shortcoming with current proliposome preparation methods is the lengthy processing time to remove solvent due to the need for extra steps or sometimes requiring cryo-protectants. The use of organic solvents also brings regulatory hurdles, as the final products may contain organic residues $(19,30)$.

To address the shortcomings of proliposomal production a propitious method is to use supercritical fluid (SCF) technologies $(2,38)$. In addition the conventional methods for preparation of proliposomes (Table 1) suffer from wide batchto-batch variability, do not produce vesicles with desirable particle size distribution $(39,40)$. The conventional methods have demonstrated the production of proliposomes but they have significant drawbacks that SCF based methods could address.

In this review, current SCF methods to produce proliposomes are outlined, with the solvent methods listed first, followed by the anti-solvent SCF methods. The principles, advantages and disadvantages for each SCF method are highlighted, along with the typical characterisation studies performed. The key differences between methods will be discussed, to help identify the important factors of each SCF method described. Throughout this paper, the abbreviation PL is used to mean pro- or pre- liposomes. The literature search methodology involved the use of Medline and Scopus using the search terms: supercritical fluid, proliposome, and preliposome. 
Table 1. Conventional preparation methods for liposomes and follow-on steps to form proliposomes.

\begin{tabular}{lll}
\hline Method & $\begin{array}{l}\text { Procedure } \\
\text { (steps involved) }\end{array}$ & $\begin{array}{l}\text { Follow-on method/s to } \\
\text { form solid state product } \\
\text { (proliposomes from } \\
\text { liposomes) }\end{array}$ \\
\hline $\begin{array}{l}\text { Bangham; } \\
\text { Also known as the hand- } \\
\text { shaken or the thin-film }\end{array}$ & $\begin{array}{l}\text { 1) Mixture of phospholipid } \\
\text { and cholesterol dispersed in organic solvent }\end{array}$ & $\begin{array}{l}\text { Collect solid } \\
\text { proliposomes after step 2 }\end{array}$
\end{tabular}

distribution on carrier $(1$, $18,21)$

3) Hydration of solid lipidic film prior to use

Reverse-phase evaporation vesicles (REV) (22)

Solvent injection (either with ethanol or ether) $(27,28)$

Detergent dialysis (29)

Effervescent (30-32)

Heating method (33)

Supercritical reverse phase evaporation (SCRPE) (34)

Spray-drying (7)

Freeze-drying $(35,36)$
As above for steps 1) and 2), then

3) Lipidic film purged with nitrogen and re-dissolved in organic solvent

4) Aqueous buffer introduced and organic solvent removed under continuous nitrogen

As above for step 1), then 2) Inject lipid solution into aqueous media to form liposomes

1) Mixture of phospholipid and cholesterol dispersed with detergent (forming micelles)

2) Detergent removed by dialysis forming unilamellar liposomes

3) Further possible step to reduce size, e.g. homogenisation

1) Mixture of phospholipid

and cholesterol dispersed in organic solvent

2) Ethanol solution filtered through membrane, transferred and stirred in citric acid $(5 \% \mathrm{w} / \mathrm{v})$ for $30 \mathrm{~min}$. 3) Add into a carbonic acid monosodium salt solution $(5 \% \mathrm{w} / \mathrm{v})$ and stir until milk white suspension formed

1) Disperse lipids in water

2) Heat ingredients in $3 \%$ glycerol to $120^{\circ} \mathrm{C}$ while stirring

1) Disperse lipids in $\mathrm{scCO}_{2} /$ ethanol

2) Inject aliquots of water into emulsion while stirring under SC conditions, then release pressure

1) Disperse lecithin and mannitol in chloroform

2) Sonicate solution

3) Spray-dry

4) Hydrate in phosphate buffer saline by stirring for 45 minutes

1) Disperse lipids with sucrose in tert-butyl alcohol and water

2) Sterilise by filtration and fill into vials for freezedrying

3) Freeze-dry: 3a) freeze at $-40^{\circ} \mathrm{C}$ for $8 \mathrm{~h}, 3 \mathrm{~b}$ ) dry at $25^{\circ}$

$\mathrm{C}$ for $48 \mathrm{hrs}$, and $3 \mathrm{c}$ ) final drying at $25^{\circ} \mathrm{C}$ for $10 \mathrm{~h}$

4) Form liposomes by hydration
Freeze-drying $(23,24)$, or fluid-bed drying (25), or spray-drying (26)

One follow-up step from above (56-59)

One follow-up step from above (56-59)

Freeze solution $\left(-60^{\circ} \mathrm{C}\right)$ and lyophilize for $36 \mathrm{~h}$ and collect solid freezedried product

One follow-up step from above (56-59)

One follow-up step from above (56-59)

Stop after step 3, to collect solid proliposomes

Stop after step 3, to collect solid proliposomes

\section{Supercritical fluid technologies}

Supercritical fluid technologies are a relatively new field of research in pharmaceutical sciences and have a range of applications including extractions, chromatography, and particle formation. In the case of particle formation, which is where PLs preparation is a subcategory, the SCF is able to facilitate precipitation much faster than 
in liquids. By rapidly exceeding the saturation solubility of a solute, through dilution and/or depressurisation, SCF processing enhances nucleation and crystal growth (41). The SCF technologies are able to yield nano-/micro- and regularly sized particles. SCFs themselves exist in the pressure-temperature curve above both critical temperature and critical pressure where the physico-chemical properties of the pseudo-state are intermediate between that of a gas and a liquid (Table 2). Specifically, SCFs exhibit higher diffusivity than a liquid but lower viscosity than a liquid, combining gas and liquid solvent properties together (Table 3).

Supercritical fluid processing operates at mild and inert conditions making it possible to work with thermo-sensitive compounds including proteins $(44,45)$. The solvent power of the SCF means there is enormous potential to diminish or even eliminate the need for organic solvents $(10$, 46), so SCF solvent technologies are GMP compliance ready, and can provide high quality products $(47,48)$. The solvent power of SCFs is superior to that of conventional solvents, which can improve the mixing of excipients and APIs to prepare solid or molecular dispersions (43). It is the SCF solvent methods that do not rely on organic solvents and the area which has the greatest potential and needs to be a focus of future research.

The versatile properties of SCFs have been used to solubilize poorly-water soluble compounds which can be manipulated by changing the temperature and pressure during processing (30, 49). Even a small change in pressure for instance, 20 bar, can increase the solubility of a compound in the SCF by many fold. For example, the solubility of progesterone in supercritical $\mathrm{CO}_{2}$ $\left(\mathrm{scCO}_{2}\right)$ increases 4 times at $60^{\circ} \mathrm{C}$ when pressure is increased from $110-170$ bar (50). As a solvent, the SCF state of carbon dioxide $\left(\mathrm{CO}_{2}\right)$ is therefore superior to its liquid form due to this "solvent tunability property". There are a range of different compounds that can be brought into the supercritical fluid state, Table 2 (42). As an example, $\mathrm{CO}_{2}$ is frequently used as a SCF due to its low critical temperature $\left(31.5^{\circ} \mathrm{C} / 90^{\circ} \mathrm{F}\right)$ and critical pressure of 73 bar (Figure 2).

These relatively mild SCF forming properties helps the usability of $\mathrm{CO}_{2}$ for both polar and nonpolar API molecules, and allow for processing of thermo-sensitive compounds, both API and nonAPI. Furthermore, $\mathrm{CO}_{2}$ is considered non-toxic, non-immunogenic, affordable, readily available, non-corrosive, stable across a wide range of temperatures and pressures. In terms of APIs with higher boiling points (most APIs would be considered non-volatile), which would normally be difficult dissolve without the use of an organic solvent or heat, can however be dissolved with $\mathrm{ScCO}_{2}(13)$.

Table 2. Critical properties of different compounds used in supercritical fluid technology (42).

\begin{tabular}{llll}
\hline Compound & $\mathrm{Tc}^{*}\left({ }^{0} \mathrm{C}\right)$ & $\mathrm{Pc}^{* *}(\mathrm{bar})$ & Note \\
\hline Ammonia & 132.6 & 113 & Green \\
Carbon dioxide & 31.5 & 73 & technology \\
Nitrogen & -147 & 34 & fluids \\
Water & 374.5 & 221 & \\
Benzene & 289 & 49 & \\
Chlorotrifluoromethane & 111.9 & 39 & \\
Ethylene & 9.3 & 51 & \\
Ethane & 32.5 & 49 & \\
Methanol & 240.6 & 49 & \\
n-Propane & 93.9 & 53 & \\
Dimethyl ether & 127 & & \\
\hline
\end{tabular}

$* \mathrm{Tc}=$ critical temperature; $\mathrm{Pc} * *$ - critical pressure

Table 3. General orders of magnitude of physical properties in three states of matter (43).

\begin{tabular}{lccc}
\hline State of matter & Density $\times 10^{2}\left(\mathrm{~kg} \cdot \mathrm{m}^{-3}\right)$ & $\begin{array}{c}\text { Property } \\
\text { Diffusivity } \times 10^{-3}\left(\mathrm{~cm}^{2} \cdot \mathrm{s}^{-1}\right)\end{array}$ & Viscosity $\times 10^{-4}\left(\mathrm{~kg} \cdot \mathrm{m} \cdot \mathrm{s}^{-1}\right)$ \\
\hline Liquid & $6-16$ & $0.002-2$ & $2-30$ \\
SCF (Pc: Tc) & $2-5$ & 0.7 & $0.1-0.3$ \\
4Pc: Tc & $4-9$ & 0.2 & $0.3-0.9$ \\
Gas & $0.006-0.02$ & $0.1-0.4$ & $0.1-0.3$ \\
\hline
\end{tabular}


Furthermore, SCF technologies which rely on $\mathrm{CO}_{2}$ are 'green' technologies (Table 2) because the gas collected is released back into the atmosphere, resulting in no net change in atmospheric $\mathrm{CO}_{2}$ levels. Some SCFs require much higher temperatures and pressures for operation (e.g. the critical point of water is $647^{\circ} \mathrm{C}$ and 220 bar and for ammonia is $133^{\circ} \mathrm{C}$ and 113 bar) resulting in mechanical stresses on equipment and difficulty in maintaining safety standards (20). Interestingly, SCFs can also act as an anti-solvent in order to rapidly precipitate out desired components. The supercritical anti-solvent process (SAS) and SASderived processes, have been utilised to form proliposomes. These different SCF methods will be separately discussed for clarity in the following sections.

\section{Supercritical fluid methods for proliposome preparation}

Supercritical fluid technologies was firstly researched and established as an alternative to conventional methods to prepare proliposmes, by Magnan, et al in 2000 (38). Supercritical fluid technology enables precise control and manipulation of SCF solutions and suspensions during processing at the small scale using micrometer valves. The processing of a SCF involves the use of the desired temperature and pressure for a pre-determined time period. After SCF processing, the SCF is extracted by release of a valve, which can be opened slowly using graduations marked on the valves or rapidly, leaving well-defined proliposome particles. To date, a small number of SCF papers, as detailed in Table 4, have been used to produce proliposomes. It should be noted again, that the majority of the SCF methods used to produce proliposomes are anti-solvent, that is require organic solvent, whereas there are only two SCF solvent methods. It is the latter, SCF solvent methods which offer the best potential, even if only to avoid the use of any organic solvents and from a regulatory perspective this will be of significance. The SCF solvent methods are outlined first. Figure 3 shows the general rig assemblies for different supercritical fluid technologies.

\section{Particles from gas-saturated solution method (PGSS)}

Utilising a supercritical fluid as a co-solvent was first described by Graser, et al., to form particles from gas saturated solutions (PGSS) (60). This technique has since been researched modestly to produce solid-state proliposomes. By exploiting the ability of the SCF to diffuse into solute of a particular solution, this technique causes an expansion of solvent/co-solvent volume, resulting in significant reduction in solution viscosity and modifying melting points of the binary/ternary systems. With additional pumping of supercritical fluid into the system the pressure increases and a gas-saturated solution is produced. The general experimental setup of this method is shown in Figure 3D. This is different to the SAS methods, not only by way of the solvent effect, but also in that there is another chamber for the sample (bioactive/other ingredients in solution) to be preloaded and this is known as the sample cylinder.

The PGSS method also varies in the steps taken to complete a batch run. There are three main steps, the first is to prepare a simple, ideally solvent-free, homogenous solution (it could also be a suspension or emulsion), the second step includes mixing of the solution with the SCF to achieve a gas-saturated solution, and the final step is performed by mixing the solution with SCF further via a capillary where the mixture if subject to rapid atmospheric expansion. Here the SCF evaporates as a gas, leaving the precipitated microparticles in the precipitation chamber. This technique offers many advantages in terms of having a lower operating pressure compared to other SCF methods, no need to use organic solvent. The amount of carbon dioxide consumed is much lesser compared to previously outlined SAS methods and precipitated particles come with small size and narrow particle size distributions. It is important to note that the PGSS method has also been developed using the SCF as an anti-solvent to form a suspension. Both types of PGSS methods (one solvent, one other anti-solvent) have been researched for proliposome preparation, as follows;

In a study by Varona, et al., PGSS method was applied to prepared proliposomes encapsulating natural antimicrobial and antiviral avandin oil, a volatile, easily degradable, and hydrophobic compound (54). In this study, an emulsion was prepared by adding phospholipid compound (lecithin) within different ratios of deionised water at $50^{\circ} \mathrm{C}$, lavandin oil was then added gradually to obtain an emulsion. The emulsion was processed further to improve the homogeneity by means of a homogenizer to achieved fine suspended droplets. Once added to the sample SCF cylinder, $\mathrm{scCO}_{2}$ was pumped in, resulting in sudden reduction in the viscosity of emulsion facilitating the forming of a new emulsion containing dissolved carbon dioxide into the dedicated precipitation chamber. 


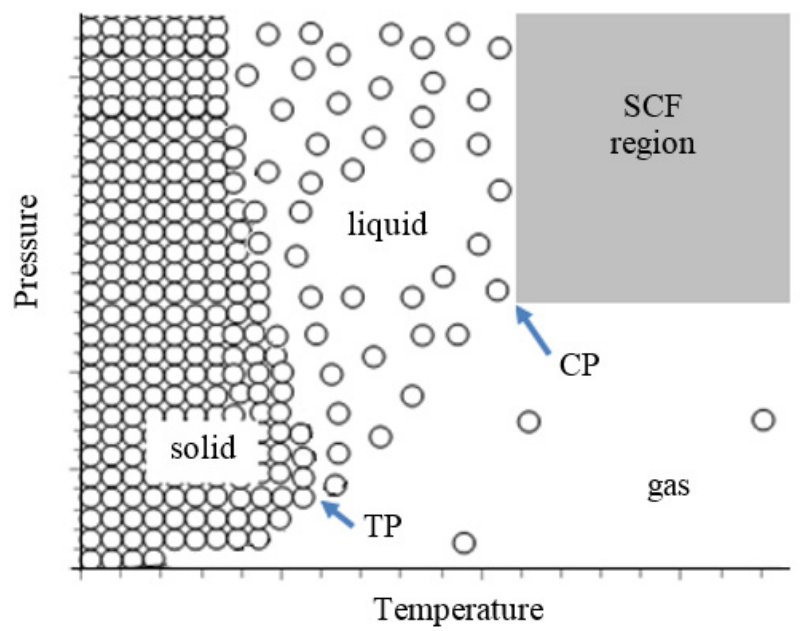

Figure 2. Typical phase diagram for carbon dioxide. $\mathrm{TP}=$ triple point, $\mathrm{CP}=$ critical point, $\mathrm{SCF}=$ supercritical fluid.

Consequently, precipitated small fine dry particles form on expansion. This method produced spherical micro-sized proliposomes which under hydration formed mulilamellar liposomes with size range between $0.45-1.47 \mu \mathrm{m}$ (54).

In 2012 Paz, et al., applied the PGSS method to produce $\beta$-carotene encapsulating proliposomes (9). In this study, carbon dioxide was used to saturate an aqueous suspension of $\beta$-carotene using a static mixer at high pressure. First, an emulsion was prepared by mixing phospholipid compound (lecithin) with water by means of stirring, to obtain concentrations of 52,62 , and $72 \mathrm{~g} / \mathrm{L}$. Three final concentrations of lecithin were used for the purposes of a factorial design study. Then $\beta$ carotene was dissolved in dichloromethane (DCM) and added to the phospholipid emulsion and further homogenised to form a macro-emulsion. An evaporation phase using a rotary evaporator was conducted to eliminate the organic solvent and obtain a solvent free emulsion (9). The prepared macro-emulsion was exposed to $\mathrm{scCO}_{2}$ at a flow rate of $15 \mathrm{~kg} / \mathrm{h}$. Once selected conditions were met, the system was depressurised to atmospheric conditions within the spray tower, consequently generating small dry particles, which collected for characterisation. This method formed proliposomes with the size $10-500 \mu \mathrm{m}$ and encapsulating efficiency $30-60 \%$, which under hydration formed liposomes with size $1-6 \mu \mathrm{m}$ (9).

Data presented by Varona, et al., showed that increases of pre-expansion temperature can enhance the encapsulating efficiency of lavandin oil, similarly, increasing pressure was found to promote the encapsulating efficiency (54). While increases in the gas to product ratio (GPR), was found to have a significant reduction effect on the encapsulating efficiency. This was explained by the evaporation loss of essential oil during mixing SCF and depressurization phases (54). Paz, et al., had promising encapsulating efficiencies compared to that achieved by Varona, et al., with a major difference being higher GPRs (9). It was stated that increasing the GPR leads to accelerated mass transfer in the mixing phase, thus increasing the amount of carbon dioxide that can be dissolved in solution, and hence improving atomisation of solution to forms particles with better uptake of the bioactive.

The concentration of phospholipid was also found to be an important influence on the particle size. Varona, et al., (54), found in contrast to Paz, et al. (9), that increasing phospholipid concentration in the organic solvent $(52-72 \mathrm{~g} / \mathrm{L})$ resulted in significant reduction in particles size. This was explained due to the co-solvent role for phospholipids that enables more carbon dioxide to be dissolved with the solution (co-solvent effect) leading to enhance atomization (54). This method also used the highest flow rate $(15,000 \mathrm{~g} / \mathrm{h})$ compared to the other methods used for proliposome preparation.

\section{Supercritical anti-solvent (SAS) process}

The SAS technique may be considered the most attractive, as it offers many advantages it terms of lower residual solvent content, being a relatively simple process, and able to process molecules with poor solubility in the SCF as the SCF is used as an anti-solvent (20). SAS methods are the most commonly reported methods for proliposome preparation in the literature. Generally, the API molecule is first dissolved in an organic solvent and this solution is fed through a tube into another 
tube housing a SCF. In these methods, the SCF plays an anti-solvent role, as the organic solvent and SCF mix, the bioactive compound precipitates out. This technique exploits the fact that an organic solvent can dissolve a large amount of gas by forming a mutual miscibility of organic and SCF phase, in which the proliposome components would precipitate out on exposure to the SCF (49). As the organic solvent is diluted in the SCF phase, the solutes would form a solid-state proliposome which would have API incorporated.

It is worth mentioning that there are somewhat interchangeable terms regarding the way the SCF phases are formed. By convention the gas antisolvent (GAS) method (presented in more detail in the subsequent section) is one where a compressed gas is progressively added to a solution containing a bioactive and primary solvent until a SCF/dense gas state is reached, whereas the SAS method has the solution of bioactive and solvent sprayed continuously into a SCF or as the case may be, a dense gas (near supercritical fluid conditions) (61). For the purpose of this review, where it is obvious for the SAS method described, it is assumed that a SCF state has been achieved, unless otherwise stated and the API solution is sprayed continuously into the SCF phase. Both the SAS and GAS methods use a setup similar to that shown in Figure $3 \mathrm{~A}$.

Magnan, et al., was the first to implement the SAS method to produce proliposomes (38). This study was carried out to determine the influence of operating pressure, solution flow rate, and solute concentration on the generated particles. A solution was prepared by dissolving soy lecithin S75 (a mixture of various phospholipids, Table 3). After the desired temperature and pressure were reached, the solution (of ethanol) with a flow rate range of $10-28 \mathrm{~mL} / \mathrm{h}$ was introduced into the precipitation chamber $(500 \mathrm{~mL})$. At steady state and within desired operating conditions, a solution was sprayed via an atomising capillary (internal diameter of $150 \mu \mathrm{m}$ ) into the dedicated precipitation chamber forming small droplets of solution with co-current stream of $\mathrm{scCO}_{2}$ (flow rate $400 \mathrm{~g} / \mathrm{hr}$ ) (38). It was found that the high solution flow rate enhances the diffusing of SCF to form solution droplets, as the solvent is miscible with the SCF, thus inducing precipitation of microparticles. This method produced dry (residue free), spherical proliposomes with size range between 1 $-40 \mu \mathrm{m}$ (38). It should be noted that use of an atomising capillary (nozzle) allows for the reduced solution flow rate. It has been suggested that to ensure the formation of droplets out of a capillary, the solution must be pumped into precipitation chamber with a flow rate of at least $180 \mathrm{~mL} / \mathrm{h}(62)$. This is an important aspect of this SAS method compared to other anti-solvent SCF methods because without atomising it is more difficult to form smaller particles. The remaining SAS methods outlined did not reach atomising flow rates, however they employed the continuous API loaded solution into the SCF phase where the SCF acted as an anti-solvent.

Recently, Liu, et al., implemented the SAS method to prepared 10-hydroxycamptothecin (derived from camptothecin) loaded proliposomes (59). The general experimental set-up was similar to that shown in Figure 3 and the parameters are listed in Table 3. In brief, solutions of API and liposomal components were made with organic solvents, to give a final concentration of $1 \mathrm{mg} / \mathrm{mL}$. Supercritical $\mathrm{CO}_{2}$ was pumped into the precipitation chamber with a constant flow rate of $20 \mathrm{~g} / \mathrm{min}$. After the desired temperature $\left(30-50^{\circ} \mathrm{C}\right)$ and pressure ( 80 - 160 bar) was reached, a solution was pumped through an injector inlet (also known as the expansion capillary) with a constant flow rate $(0.3-1.5 \mathrm{~mL} / \mathrm{min})$ into the precipitation chamber. Upon precipitation and washing phase completion, particles were collected to be characterised. The size, shape and API loading of the produced particles were influenced of changing the mass ratio of lipid components, API concentration, and various operating conditions. The results from this study showed that proliposomes can be formed, which under hydration gives spherical, near spherical, and clavate shaped liposomes. Under optimisation conditions $\left(40^{\circ} \mathrm{C}, 160\right.$ bar, solution flow rate 18 $\mathrm{mL} / \mathrm{h}$ ), the precipitate particles were in the clavate shape giving drug loading (DL) of $5.33 \%$, entrapment efficiency (EE) of $85.28 \%$ and relatively narrow particle size distribution with a mean diameter $\left(\mathrm{PD}_{50}\right)$ of $209.8 \pm 38.4 \mathrm{~nm}$ with an acceptable residue limit (ICH guidelines) (59).

Recently Naik, et al. utilised a SAS method to prepare docetaxel encapsulated PEGylated liposomes from proliposomes (53). Docetaxel is an anticancer agent used in the treatment of a range of solid tumours. The solution contained different mass molar ratio of bioactive, phospholipids, and cholesterol, dissolved in a mixture of organic solvents. SCF was pumped into the precipitation vessel with constant flow rate (ranging between 2$7 \mathrm{~g} / \mathrm{h}$ ), after desired and pressure (ranging between 100 - 220 bar) reached the bioactive containing solution was pumped with constant flow rate 9 $\mathrm{mL} / \mathrm{h}$ into the precipitation chamber. There is no mention about diameter of the nozzle or whether it is a capillary or actual nozzle, given the solution 
rate of only $9 \mathrm{~mL} / \mathrm{h}$ this may not have been enough for atomisation, as will be discussed later and the authors have referred to this as a SAS method. Nevertheless, due to the simultaneous diffusion of SCF into the organic solvent (antisolvent effect), small particles (proliposomes) were precipitated. Data showed that docetaxel loaded PEGlyated proliposomes were successfully formed and with hydration produced PEGlyated liposomes with a size range between $200-300 \mathrm{~nm}$, in spherical and small unilamellar shape (53).

In 2011 Lesoin, et al., applied the ASES method to produce proliposomes and then liposomes encapsulating lecithin (56). Solution was prepared by mixing $2 \mathrm{~g}$ of soy lecithin with organic solvent (ethanol) to obtained final concentration of solute ranging between 15-25 $\% \mathrm{w} / \mathrm{w}$. Carbon dioxide was brought to SCF conditions and the solution was pumped with a flow rate of $22.8 \mathrm{~mL} / \mathrm{h}$ into the precipitation chamber a capillary (diameter $127 \mu \mathrm{m}$ ). The precipitation of small particles (proliposomes) were collected after $\mathrm{CO}_{2}$ washing and depressurization phases to be characterised. Results showed that particles distribution size was bimodal with two population of particles size between $0.1-500 \mu \mathrm{m}$ but the majority of particles size ranging between $0.1-1 \mu \mathrm{m}$ (56). The prolipsomes were hydrated with stirring which helped to form a homogenous mixture of liposomes. As noted later by the same research group, a major drawback of this method was that the proliposomes would aggregate (between phospholipids) spontaneously upon contact with air, so they had to be handled with almost impractical precautions before hydration (44). This study did not include an API in the preparation of the proliposomes and only used a solution flow rate of approximately $23 \mathrm{~mL} / \mathrm{h}$, rendering atomisation unlikely to have been reached. Noting the fact that an API was not present as an ingredient, the particle size distribution was relatively narrow for almost $90 \%$ of the particles $(0.1$ to $1 \mu \mathrm{m})$.

\section{Gas anti-solvent (GAS) method}

In this semi-continuous method the experimental apparatus is presented in Figure 3A. Apart from the progressive addition of the SCF phase into the API solution, which is the reverse of the SAS method, the GAS unit is composed of two structures; one designed to hold the solution of bioactive, phospholipid, and sufficient organic solvent to dissolve the solutes and this solution is under ambient temperature and pressure. While the other part is where precipitation takes place, hence this part is known as the precipitation chamber. This is a dedicated vessel designed to withstand high pressure and is housed by a water bath/heat pump to reach a desired temperature.

This process has been conducted in the following order; a mixture containing solute is dissolved in an organic solvent which is injected into the precipitation chamber, carbon dioxide in its liquefied state is then pumped into the same chamber. The precipitation chamber is pre-heated to prevent cavitation prior to the above step. Then the precipitation chamber is pressurised and the solution:SCF ratio is decreased several fold (63), leading to rapid supersaturation, which decreases the solvating power of the organic solvent drastically, causing nucleation and crystal growth. After the precipitation phase, the remaining solvent is washed out by pure carbon dioxide to eliminate organic solvent traces in precipitate particles, which settle on the bottom of the precipitation chamber (62). This method offers to produce a higher yield of particles compared to the SAS method due to the longer residence time in the precipitation chamber which can also affect the morphology of precipitate particles.

A modified GAS method developed by Karn, et al., in 2013, describes a simpler, innovative, and scalable SCF method compared to other liposomal preparation methods (8). In this method an immunosuppressive API (Cyclosporine A), used a highly lipophilic model bioactive, was loaded into the liposome's bilayer to improve drug efficiency and stability. A mixture of solute (Cyclosporine A) with the liposomal ingredients was dissolved in ethanol, this solution was loaded into the precipitation chamber accompanied with lactose. The carbon dioxide was progressively introduced to the precipitation chamber by use of a syringe pump. Pressure ranging from 80 to $250 \mathrm{bar}$ and temperature ranging from 35 to $50^{\circ} \mathrm{C}$ was investigated in order to find the effects the final DL of proliposomes/liposomes. It was found that supercritical fluid conditions (temperature $45^{\circ} \mathrm{C}$ and pressure 100 bar), but not subcritical conditions, were able to produce multilamellar liposomes on hydration. Liposome sizes ranged between $0.7-1.4 \mu \mathrm{m}$, were homogenous, and the produced liposomes were physically and chemically stable over 14 weeks (8). When pressure was kept constant (10 MPa or $100 \mathrm{bar}$ ), it was observed that temperature had varying effects; increasing the operating temperature $\left(40-45^{\circ} \mathrm{C}\right)$, resulted in a higher yield (87.2 - 89.3\%) and DL increased from 20 to $20.5 \% \mathrm{w} / \mathrm{w}$, while increasing the temperature further $\left(45-50^{\circ} \mathrm{C}\right)$, resulted in a lower yield (89.3 - 79.7\%) and DL dropped from $20.5-18 \% \mathrm{w} / \mathrm{w}(8)$. The authors claimed that the 
changing yields and DLs occurred due to the different roles of SC carbon dioxide within the process, at a lower temperature, the antisolvent role can facilitate extraction of the organic solvent from solution, and at higher temperatures the SC carbon dioxide acts as solvent. The solvent role leads to a larger dissolved portion of solute, and hence the process yield will decrease drastically, and as a consequence DL decreased. Similarly, when pressure within the precipitation chamber was increased (100- 250 bar), there was a significant reduction in yield $(87.2-42.1 \%)$ and DL $(20$ - 9.35 $\% \mathrm{w} / \mathrm{w})(8)$. Overall, this method produced the highest yielding product (up to $89.3 \%$ ), unfortunately neither the solution or $\mathrm{CO}_{2}$ flow rates were recorded and the DL was variable. It must be noted that this study also utilised some of the highest pressures (up to 250 bar) which may help explain the high yields observed.

\section{Aerosol solvent extraction system (ASES)}

Another semi-continuous antisolvent method called the aerosol solvent extraction system (ASES), first developed by Bleich and coworkers in 1993, was shown to enhance the mixing between the solution and $\mathrm{scCO}_{2}$ and to offer more effective control over the size of generating particles (62). Instead of a conventional SCF mixing process where a solution enters the precipitation chamber via a capillary, a solution using the ASES method has been introduce into the precipitation chamber via a nozzle, to form smaller droplet sizes, therefore smaller particles. This is also known as the supercritical assisted atomisation (SAA) method. This process increases the contact surface area between solution and SCF, consequently increasing the rate of diffusion of the SCF, hence, improve the nucleation process. Essentially, at lower flow rates ASES is a better way for atomization to occur than by the SAS method. The experimental set up is similar to that for SAS and GAS except that there is a basic nozzle instead of a capillary (injector inlet) (Figure 3B). As noted by Bleich, et al. that the nozzle helps to form smaller droplets, hence smaller particles, however this difference is not so clear at high liquid flow rates with capillaries (61). For methylene chloride the jet breakup disappears for a capillary of $150 \mu \mathrm{m}$ and flow rate of $180 \mathrm{~mL} / \mathrm{h}$, which is when atomization is realised (61). Furthermore, the nozzle vs. capillary effect may not always matter, as the material being investigated is not always affected by the SCF conditions/parameters, e.g. polymers exposed to variable SCF temperatures and pressures seems to have limited effects on particle morphology (64).
In 2006 Kunastitchai, et al., implemented an ASES method to form dry microparticles containing miconazole (51). The experimental set up was described without the use of a diagram but it was noted that the spray rate was $180 \mathrm{~mL} / \mathrm{hr}$, which is what is required to atomise the bioactive solution without a nozzle. This study investigated the influence several factors, including the solute concentration, and surfactant effects on the microparticles formed. Two different solution concentrations were studied (19 and $38 \% \mathrm{w} / \mathrm{w})$ mixed with phosphatidylcholine (PC) and cholesterol in two different mixing ratios (10:0 and $8: 2 \mathrm{w} / \mathrm{w})$ dissolved in organic solvents $(8: 2 \mathrm{w} / \mathrm{w}$ ethanol and methylene chloride) with and without Poloxamer 407 (51). SC carbon dioxide was introduced into the precipitation chamber (volume of which was not stated), after the pre-set temperature and pressure were obtained, solution pumped into the precipitation chamber through a nozzle (diameter of $0.4 \mathrm{~mm}$ and angle of spraying was $15^{\circ}$ ) to form small solution droplet within cocurrent flow of $\mathrm{scCO}_{2}$, leading to precipitation of small particles (51). On drying and washing with pure carbon dioxide for 3 to $4 \mathrm{hr}$ the system was depressurized, and sample collected for characterization. The process produced cubic and rod-like shaped particles with some aggregation. Complete hydration the solid particles at $55^{\circ} \mathrm{C}$ produced liposomes with particle size range between $2.7-9.4 \mu \mathrm{m}$, which depended on the $\mathrm{pH}$ of the hydration medium. Generally, those hydrated with a higher $\mathrm{pH}$ (7.2) possessed larger particles with higher EE (51).

Bridosn, et al., in 2006, applied modified version of the ASES method to produce phospholipids powders (65). In this study, four different solutions (of $10 \mathrm{~mL}$ each) composed of different phospholipids were dissolved in ethanol to obtained a final concentration of $45 \mathrm{mg} / \mathrm{mL}$. The solution and $\mathrm{scCO}_{2}$ mixing in the precipitation chamber was typical for the ASES method, however it was additionally housed in a T-shaped assembly within a water bath. The significance of which is not known, although it was indirectly stated that the T-shaped piece may have affected the ethanol expansion, therefore the supersaturation rate of the phospholipids on contact with the SCF. Once the desired operation conditions were reached, solution was sprayed via an inlet capillary into T-piece of the precipitation chamber. The study also investigated the influence of different parameters, such as changing the type of lipid (listed previously), solution flow rate (15 $30 \mathrm{~mL} / \mathrm{h}$ ), SCF flow rate (between $15-20$ $\mathrm{mL} / \mathrm{min})$, and the capillary diameter $(75-150 \mu \mathrm{m})$ 
(65). This method obtained fined particles with diameter size range between $1-3 \mu \mathrm{m}$ and these proliposmes under hydration produced liposomes with size ranging between $1-10 \mu \mathrm{m}$. The down side to this study was that the resulting liposomes are considered to be too big for use as a drug delivery system. It was suggested that larger sized liposomes can be used to facilitate encapsulating poor-water API intended to be administered orally (65).

\section{Solution enhanced dispersion by supercritical} fluids (SEDS)

This technique was first developed by Hana and York in 1994 at Bradford University, UK (52). This research received a patent essentially on the use of a coaxial nozzle along with the other SAS method parameters. The solution enhanced dispersion by supercritical fluid or SEDS offers several advantages over other SAS methods, in terms of being agglomeration free, having a shorter drying time, more readily scalable, can achieve small particles size using lower solution flow rates (less than $180 \mathrm{~mL} / \mathrm{hr}$ ). A reduced washout phase time period can also eliminate traces of solvent residues within particles. Experimental setup for this approach is slightly different from ASES and other SAS methods in that the coaxial nozzle (double or triple component) is used as the entering route for both bioactive solution and the supercritical fluid, see Figure 3C.

In a study by Xia, et al., using the anti-solvent method (SEDS), lutein and hydrogenated soya phosphatidylcholine (HPC) was dissolved in a mixture of dichloromethane and ethanol (ratio 40:1 $\mathrm{v} / \mathrm{v}$ ) with a final concentration of $0.73 \mathrm{mg} / \mathrm{mL}$ (55). Carbon dioxide was liquefied and then pumped into a $200 \mathrm{~cm}^{3}$ precipitation chamber via a coaxial nozzle (inner diameter $0.2 \mathrm{~mm}$ ) and the lutein solution was introduced at a constant flow rate of $60 \mathrm{~mL} / \mathrm{hr}$ (55). The coaxial assembly allows for the rapid mixing of $\mathrm{scCO}_{2}$ and solvent leading to a rapid decrease in the solvating power of organic solvent, simultaneously the lutein reaches supersaturation equally rapidly, resulting in precipitation of proliposomes in the precipitation chamber. Investigated values for pressure with precipitation chamber ranged between $80-120$ bar, with temperatures between $35-55^{\circ} \mathrm{C}$. The optimization process demonstrated the highest DL was obtained with a pressure of 80 bar and a temperature of $35^{\circ} \mathrm{C}$. In was also found that an increased pressure from $80-120$ bar by the SCF during precipitation favoured the formation of smaller proliposome particles. This SEDS method produced spherical particles with size around 200 $\mathrm{nm}$ and narrow PDI, lutein was successfully embedded into proliposomes with loading efficiency reached to $55.04 \mathrm{mg} / \mathrm{g}$ (55). In another study by Xia, et al., in 2011 using a similar preparation method as above, it was found that after the hydration, the formed liposomes encapsulating vitamin $D_{3}$ had a size of range of between $1-2.7 \mu \mathrm{m}$ (57). The proliposomes are reportedly easily hydrated, forming unilamellar liposomes with entrapment efficiency for both studies reaching within the $90 \%$ region.

In a subsequent study, Xia, et al., implemented the SEDS method again to prepare Coenzyme Q10 (CoQ10) encapsulated proliposomes (58). The use of proliposomes and ultimately liposomes was a strategy used to overcome the solubility difficulties exhibited by CoQ10, which is considered a 'brick dust molecule' with poor aqueous solubility and poor absorption through biological tissues. In brief, a solution was prepared by mixing the bioactive with phosphatidylcholine (PC) between ratios of 1:10 and 2:10 (w/w), to which cholesterol was added within range ratio of $1: 1$ and $1: 3(\mathrm{w} / \mathrm{w})$. These compounds were dissolved in an organic solvent mixture (dichloromethane and ethanol $13: 12 \mathrm{v} / \mathrm{v}$ ) to obtained solute concentration of 1.8 $\mathrm{mg} / \mathrm{mL} \cdot{ }^{[58]} \mathrm{SC}$ carbon dioxide was pumped into a $200 \mathrm{~cm}^{3}$ precipitation chamber via a coaxial nozzle as used previously, the solution had a flow rate of $60 \mathrm{~mL} / \mathrm{h} \mathrm{(58)}$. The investigated parameters included the pressure range between $80-160$ bar and temperature range between $35-55^{\circ} \mathrm{C}$ for temperature. The findings for optimised parameters were $\mathrm{T}=35^{\circ} \mathrm{C}$ and $\mathrm{P}=80 \mathrm{bar}$, weight ratios 1:10 between $\mathrm{CoQ} 10$ and $\mathrm{PC}$, and 1:3 between cholesterol and PC (58). Data from this study demonstrated that the SEDS technique can be used to produce proliposomes that under hydration can form liposomes with an estimated size of $50 \mathrm{~nm}$.

The operating temperature during SEDS processing influences the parameters of the final product. With increasing operating temperature, DL percentage decreased $(55,58)$. This phenomenon can be explained thermodynamically as increases in the system temperature leads to reducing anti-solvent capacity of $\mathrm{scCO}_{2}$, thus partial reverse extraction back to the solvent occurs, as consequence yield and DL decreases (58). The effect of temperature on yield was investigated by Kunastitchai, et al., and it was shown that decreasing temperature promoted higher yields (39). It was suggested that temperatures above the glass transition point for the phospholipids studied is avoided, which is approximately $51^{\circ} \mathrm{C}(51)$. In contrast Naik, et al., 
found no significant influence by temperature on particles size but found a significant reduction on yield, as temperature increased to $46^{\circ} \mathrm{C}$, the yield dropped to $23.6 \%$ (53). These findings were consistent with that observed by Liu, et al. (58).

The influence of pressure under the SASSEDS methods examined by Xia, et al. $(55,57$, 58). found that higher DL can be achieved with lower pressure ( 80 bar), which was explained by the authors as a result to the relatively low concentration of $\mathrm{scCO}_{2}$ within the precipitation chamber, leading to partial solvent extraction, thus effecting the time to reach the supersaturation point, and as a consequence reducing the DL level. These finding for suppression of the yield and DL at lower pressures is thermodynamically consistent, since increasing pressure (i.e. amount of SCF present) would lead to the supersaturation point quicker, resulting in a higher yield and DL. In addition Kunastitchai, et al., suggests that higher yield can be obtained at higher pressure values, provided the SCF phase has a density of more than $0.3 \mathrm{~g} / \mathrm{mL}$ (for carbon dioxide this can be achieved at 80 bar) (51). A similar pressure influence was found by Liu, et al., were a positive influence occurred on entrapment efficiency, particle size, and drug loading (59). In contrast, data presented by Lesion, et al. (56) had shown that pressure has no significant influence of the micropartciles and their morphology, which was consistent with the data by Reverchon, et al., where pressure did not have a dramatic influence on the formation of solid-lipid particles (66). This was also agreed by Bleich, et al. who studied the influence of gas density and pressure (67). The study by Naik, et al., showed that pressure had a significant influence on the particles size and the yield (53). These findings have been further confirmed by Magnan, et al., that as pressure increases from 80 to 110 bar there was no significant influence on the size and morphology of phospholipids formed (38).

The effect of solute concentration across the SAS studies examined showed positive linear relationships between increasing concentration and yield and DL. Lesion, et al. noted that an increasing of lecithin concentration, lead to bigger particles size $(30-60 \mu \mathrm{m})$ and more distinct spherical particles (56). These findings were consistent with that in the earlier work by Reverchon, et al., where it was established that higher concentrations of solute lead to early precipitation during expansion and the growth is the predominant mechanism for producing bigger particles (66). Kunastatchai, et $a l$., also noted that increasing solute concentration produced cubic and rod-like shape crystals, which was explained as a result of the linear relationship between concentration of the solute and solution viscosity (51). As the solute concentration increases the atomisation force may not be sufficient to break-up the solution to form droplets, as a consequence larger particles form. Magnan, et al., observed a similar result, where decreasing the solute concentration led to fine particles being formed, which made sense even when the solution injection rate was increased, so too did the particle size (38). At relatively low solution flow rate (10 $\mathrm{mL} / \mathrm{h}$ ) the particles were fine powders, while at higher flow rate $28 \mathrm{~mL} / \mathrm{h}$ produced bigger particles (38). One way to be able to reduce the flow rate and still achieve atomisation is through the use of a nozzle with a spray angle. It has been stated that a capillary (zero angle) requires much higher flow rates to reach atomisation from a SCF dispersed phase $(52,61)$. Figure 4 shows the different spray angles that can be created simply by using different spray nozzles.
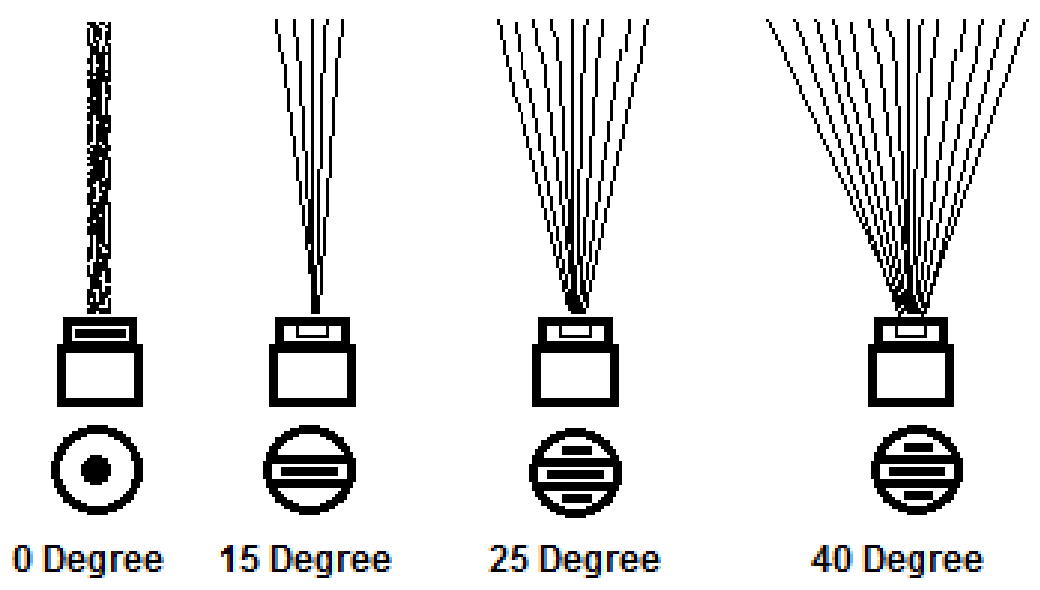

Figure 4. Nozzle and spray angles from capillary (0) to 40 degrees Celsius. 
The effects of atomisation and solute concentration are important and need to be considered when determining the SCF method parameters for a SAS type experiment. It should be noted that most SCF research has used closed systems, that is it is not possible to observe SCF related phenomenon, such as atomisation during precipitation and solubility of a solute in a SCF. Furthermore, many of the observational studies that have investigated flow dynamics through a nozzle or capillary to determine atomisation used shadow-based optical methods that cannot actually detect differences between droplet or dense gas forming sprays. As noted by Reverchon, et al., this is because both the droplet fill spray and dense gas spray or "gas-plume" are visualised as a dark shadow, making it difficult to differentiate between them (64). As also noted by Reverchon, et al. specialised light-scattering equipment is required to make diagnostic statements and definitively decide between atomised droplets and dense "gasplume". Solubility studies must be considered also, and this is important because of SCF phenomenon such as the crossover region where lower temperature at a given pressure can result in a higher solubility of a solute (50). Solvent density and solute volatility are responsible for the crossover region of a SCF and it has implications for retrograde re-crystallization. This particular effect becomes even more complicated when investigating complex mixtures such as pro/liposomes that have multi-components. In a simple binary system, there are only the solutesolvent interactions that can affect solubility. Whereas for systems with 4 or more components (e.g. phospholipids, cholesterol, drug, SCF, and possibly a polymer and co-solvent), there are multiple solute-solvent interactions, along with separate solute-solute interactions. Therefore, determining the lower and upper crossover points and critical mixture pressure (CMP) for such multicomponent systems needs to be a fundamental part of research in SCF technologies and preparation of advanced pharmaceutical delivery systems.

\section{A suitable SCF method for proliposome preparation}

To date there are only 12 articles written on the use of SCFs in the preparation of proliposomes, with the first published by Magnan et al. in 2000 (38). This reflects the unrealised potential of PLs as drug delivery systems. As described elsewhere, a breakthrough is more difficult if only academic research is developing new methods (68).

From the methods outlined, the SCF chosen was partly to do with the suitability with the physico-chemical properties of the API, that is the API solubility in the selected SCF, the SCF unit operating limits, and probably a consideration of SCF conditions and effects on the excipients used (e.g. not exceeding $60^{\circ} \mathrm{C}$ in order to preserve lipid or protein integrity). What determines the SCF solubility is not clearly understood but as a guide for $\mathrm{scCO}_{2}$ the smaller nonpolar molecules (less than 500 Daltons) are more easily dissolved at moderate pressures (41). While for larger molecules there is poor $\mathrm{scCO}_{2}$ solubility for pressure less than 500 bar. The term " $\mathrm{CO}_{2}$-philic" has been used to designate whether a molecule is miscible at a given concentration and pressure. Also the more volatile (lower melting and boiling points), the more miscible the material will be in $\mathrm{ScCO}_{2}$. Also the SCF conditions may favour certain excipients such as charged lipids, which are more aqueous soluble, therefore the use of a polar SCF such as DME or nitrous oxide would be more suitable. The selection of the SCF is an important step in the designing the most suitable SCF method in the preparation of a proliposome. It is also desirable to have research focused on the use of SCF solvent methods, that is the non-organic solvent dependent SCF methods, as the need to have environmentally friendly pharmaceutical manufacturing becomes more and more of a regulatory standard.

To date, SCF methods have not been well defined and the published methods are often difficult to follow and understand. Moreover, scale-up challenges exist such as safety in the handling of SCF and liquefied gases, plugging issues where solid-fluid equipment use closed systems, disk rupture results from brutal depressurisation, and tubing connection failure, where commonly used tubes on the small-scale are safe and reliable may not be suitable on larger scales (69). Fortunately, most of these may be challenges can be overcome, but caution and research is required to ensure there are no issues with the final setup and operation of SCF equipment. Some ideas focus on the use of automation, fluid management including recycling, and maintenance processes in the case where metal fatigue and carbon steel may be corroded (69). Where SCF prepared proliposomes have almost certain advantages in the delivery of anti-cancer agents. Once hydrated into liposomes ready for administration, there are improved pharmacokinetic outcomes (e.g. prolonged resident time) and reduced adverse-effect (e.g. avoiding phlebitis during IV injection for chemotherapy) (70). From the literature, there is already a slight preference towards anti-cancer 
agents, molecules that are large $(>500 \mathrm{~g} / \mathrm{mol})$, and poorly water soluble, as well as cancer preventative anti-oxidant agents. Another major advantage is in terms of stability, compared with conventional liposomes, SCF produced liposomes offer a dry liposome powder to be directly obtained, without the need to conduct further processing, such as spray-drying, precipitation, or freeze drying (71).

\section{CONCLUSION}

Proliposomes prepared by SCF processing for pharmaceutical drug delivery is an emerging technology. The use of proliposomes overcomes the major drawbacks of liposomes in terms of chemical and physical stability on storage and SCF technologies provide alternative methods to produce proliposomes. To date, most of the studies have utilised the anti-solvent process. However, this should not be an indication that the antisolvent methods are superior to the solvent methods and it is the SCF solvent methods that must drive the future of pro/liposome preparation. SCF methods to prepare proliposomes are promising alternatives to the existing conventional methods, the SCF solvent methods being green technology, with reduced and even eliminated organic solvent reliance, and high processing efficiency. Research needs to be focused on the non-organic solvent SCF methods, taking into account the API properties and lipid ingredients to form proliposomes. Further research is required to address some limitations and to make the production more predictable and industry 'ready' and importantly GMP compliant.

\section{DECLARATION OF INTEREST}

The authors report no conflicts of interest. The authors alone are responsible for the content and writing of this article.

\section{REFERENCES}

1. Bangham AD, Standish MM, Watkins JC. Diffusion of univalent ions across the lamellae of swollen phospholipids. J Molecular Biology. 1965;13:238-52.

2. Shaji J, Bhatia V. Proliposomes; a brief overview of novel delivery system. International Journal of Pharmacy and Biological Sciences. 2013;4:150-60.

3. Payne NI, Timmis P, Ambrose CV, Warel MD, Ridgway F. Proliposomes: a novel solution to an old problem. J of Pharmaceutical Sciences. 1986;75(4):325-9.
4. Wang J, Yoshie M, Kozo T, Tsuneji N. In vivo evaluation of doxorubicin carried with long circulating and remote loading proliposome. International Journal of Pharmaceutics. 2000;203(1-2):61-9.

5. Lee HJ, Ahn B, Paik WH, Shim C, Lee JM. Inverse targeting of reticuloendothelial system-rich organs after intravenous admistration of adriamycinloaded neutral proliposomes containing poloxamer 407 to rats International $\mathrm{J}$ of Pharmaceutics. 1996;131:91-6.

6. Wang JP, Su DS, Gu XQ. Studies on Adriamycin proliposome prepared by spray drying method. Chinese Pharmaceutical J. 1994;3:149-51.

7. Skalko-Basnet N, Pavelic Z, Becirevic-Lacan M. Liposomes containing drug and cyclodextrin prepared by the one-step spray-drying method. Drug Development and Industrial Pharmacy. 2000;12:1279-84.

8. Karn PR, Jin S-E, Lee BJ, Sun BK, Kim M-S, Sung J-H, Hwang S-J. Preparation and evaluation of cyclosporine A-containing proliposomes: a comparison of the supercritical antisolvent process with the conventional film method. International Journal of Nanomedicine. 2014;9:5079-91.

9. Paz ED, Marin A, Cocero MJ. Formulation of $\beta$ Carotene with soy bean lecithin by PGSS-drying. J of Supercritical Fluids 2012;72:125-33.

10. Beh CC, Mammucari R, Foster N. Lipids-based drug carrier systems by dense gas technology: A review. Chemical Engineering. 2012;188:1-14.

11. Krasnici S, Werner A, Eichhorn ME, Schmitt-Sody M, Paherniki SM, Sauer B, Sschulze B, Teifel M, Micheali U, Naujoks A, Dellian M. Eeffect of the surface charge of liposomes on their uptake by angiogenic tumour vessels. $\mathrm{J}$ of Cancer. 2003; 105:561-7

12. Lasic DD, Papahadjopoulos D. Chapter 6.1: Other applications in Medical application of liposomes: Elsevier B.V.; 1988.

13. Meure L, Foster N, Dehgani F. Conventional and dense gas techniques for the production of liposomes: A review. American Association of Pharmaceutical Scientists: Pharmaceutical Science Technology 2008;9:798-807.

14. Matsumura Y, Maeda H. A new concept for macromolecular therapeutics in cancer chemotherapy: Mechanism of tumoritropic accumulation of proteins and the antitumor agent smancs. Cancer Research. 1986;46(12):6387-92.

15. Y, Barenholz. Liposome application: problem and prospects. Current Opinion in Colloid \& Interface Science. 2011;6:66-77.

16. DD, Lasic. Chapter 10: Applications of liposomes. Sackmann, Edited by R. Lipowsky and E., editor: Elsevier Science B.V; 1995. 491-519 p.

17. DD, Lasic. Novel Applications of liposomes. Trends in Biotechnology. 1998;16(7):307-21.

18. Elizondo E, Moreno E, Cabrera I, Cordoba A, Veciana J, Ventosa N. Liposomes and other vesicular systems: structural characterization, methods of preparation, and use in nanomedicine. 
Progress in Molecular Biology and Translational Science. 2011;104:1-46.

19. Walde P, Ichikawa S. Enzymes inside lipid vesicles: preparation, reactivity and applications. Biomedical Engineering 2001;18:143-77.

20. Pasquali I, Bettini R. Are pharmaceutics really going supercritical? . International J of Pharmaceutics. 2008;364:176-87.

21. Akbarzadeh A, Rezaei-Sadabady R, Davaran S, Woo Joo S, Zarghami N, Hanifehpour Y, Samiei M, Kouhi M, Nejati-Koshki K. Liposome: classification, preparation, and applications. Nanoscale Research Letters. 2013;8:102.

22. Szoka F Jr, Papahadjopoulos D. Procedure for preparation of liposomes with large internal aqueous space and high capture by reverse-phase evaporation. Proceedings of the National Academy of Sciences U S A. 1978;75(9):4194-8.

23. Benjakul R, Moongkarndi P, Panyarachun B, Sarisuta $N$ Novel freeze-drying method for preparation of-mangostin dry reconstitute liposomal powder. Advanced Science Letters. 2012;11:120-5.

24. Christensen D, Foged C, Rosenkrands I, Nielsen HM, Andersen P, Agger EM. Trehalose preserves DDA/TDB liposomes and their adjuvant effect during freeze-drying. Biochimica et Biophysica Acta -Biomembranes. 2007;1768:2120-9.

25. Chen CM, Alli D. Use of Fluidized Bed in Proliposome Manufacturing. Communications. J of Pharmaceutical Sciences. 1987;76(5):419.

26. Bhai MSA, Yadav V, Mamatha Y, Prasanth VV. Liposomes: An overview. J of Pharmaceutical and Scientific Innovation. 2012;1(1):13-21.

27. Batzri S, Korn ED. Single bilayer liposomes prepared without sonication. Biochimica et Biophysica Acta -Biomembranes. 1973;298(4):1015-9.

28. Stano P, Bufali S, Pisano C, Bucci F, Barbarino M, Santaniello M, Carminati P, Luisi PL Novel camptothecin analogue (gimatecan)-containing liposomes prepared by the ethanol injection method. J of Liposome Research. 2004;14(1-2):87109.

29. Zumbuehl O, Weder HG. Liposomes of controllable size in the range of 40 to $180 \mathrm{~nm}$ by defined dialysis of lipid/detergent mixed micelles. Biochimica et Biophysica Acta -Biomembranes. 1981;640(1):252-62.

30. Patil Y, Jdhav S. Review: Novel methods for liposomes preparation. Chemistry and Physics of Lipids. 2014;177:8-18.

31. Zhao L, Wei Y, Li W, Liu Y, Wang Y, Zhong X, $\mathrm{Yu}$ Y. Solid dispersion and effervescent techniques used to prepare docetaxel liposomes for lungtargeted delivery system: in vitro and in vivo evaluation. Journal of Drug Targeting. 2011;19(3):171-8.

32. Wei Y, Xue Z, Ye Y, Huang Y, Zhao L. Paclitaxel targeting to lungs by way of liposomes prepared by the effervescent dispersion technique. Archives of Pharmacal Research. 2014;37:728-37.
33. Mozafari MR, Omri A. Importance of divalent cations in nanolipoplex gene delivery. $\mathrm{J}$ of Pharmaceutical Sciences. 2007;96(8):1955-66.

34. Otake K, Imura T, Sakai H, Abe M. Development of a New Preparation Method of Liposomes Using Supercritical Carbon Dioxide. Langmuir. 2001;17(13):3898-901.

35. Li C, Deng Y. A novel method for the preparation of liposomes: freeze drying of monophase solutions. J Pharm Sci. 2004;93(6):1403-14.

36. Cui J, Li C, Deng Y, Wang Y, Wang W. Freezedrying of liposomes using tertiary butyl alcohol/water cosolvent systems. International $\mathrm{J}$ of Pharmaceutics. 2006;312(1-2):131-6.

37. European Commision for Enterprize and Industry, ECEI. REACH - Registration, Evaluation, Authorisation and Restriction of Chemicals: European Commision; 2007 [updated 17 September 2013; cited 201425 June]. Available from:

http://ec.europa.eu/enterprise/sectors/chemicals/re ach/index_en.htm.

38. Magnan $\bar{C}$, Badens E, Commenges N, Charbit G. Soy lecithin micronization by precipitation with a compressed fluid antisolvent - influence of process parameters. J of Spercritical Fluids. 2000;19:69-77.

39. Laouini A, Jaafar-Maalej C, Limayem-Blouza I, Sfar S, Charcosset C, Fessi H. Preparation, Characterization and Applications of Liposomes: State of the Art. Journal of Colloid Science and Biotechnology. 2012;1: 147-68.

40. Karn, P.R., Cho, W., Hwang, S-J. Liposomal drug products and recent advances in the synthesis of supercritical fluid-mediated liposomes. Nanomedicine. 2013;8(9):1529-48.

41. M, Mukhopadhyay. Chapter 2 Supercritical Fluid Technology for Drug Product Development. York, P., Kompella, U.B., Shekunov, B.Y., editor. Colchester, Essex, UK: Informa Healthcare; 2008. $666 \mathrm{p}$.

42. Tabernero A, Del Valle EMM, Galan MA. Supercritical fluids for pharmaceutical particles engineering ; methods, basic fundamentals and modelling. Chemical Engineering and Processing. 2012;60:9-25.

43. A, Taleb. Part III: Supercritical Fluids. Nanomaterials and Nanochemistry. Paris, France and Berlin Heidelberg: Springer 2008.

44. Lesion L, Crampon C, Boutin O, Badens E. Development of a continuous dense gas process for the production of liposomes. J of Supercritical Fluids. 2011a;60:51-62.

45. Mayer LD, Baly MB, Hope KJ, Cullis PR. Technique for encapsulating bioactive agent into liposomes. Chemistry and Physics of Lipids. 1986;40:333-45.

46. Salmaso S, Elvassore N, Bertucco A, Caliceti P. Production of solid lipid submicron particles for protein delivery using a novel supercritical gasassisted melting atomization process. $\mathrm{J}$ of Pharmaceutical Sciences 2009;98(2):640-50. 
47. Muhrer G, Meier U, Fusaro F, Albano S, Mazzotti M. Use of compressed gas precipitation to enhance the dissolution behaviour of poorly water-soluble drug: generation of drug micropartciles and drugpolymer solid dispersions. International $\mathrm{J}$ of Pharmaceutics. 2006;308:69-83.

48. Lesion L, Crampon C, Boutin O, Badens E. $\mathrm{CO} 2 /$ water/surfactant ternary systems and liposomes formation using the supercritical CO2: A review. Colliods and surfaces. 2011b;337(1-14).

49. Fages J, Lochard H, Letourneau J, Sauceau M, Rodier E. Particle generation for pharmaceutical application using supercritical fluid technology. Powder Technology 2004;141:219-26.

50. Alessi P, Cortesi A, Kikic I, Foster NR, Macnaughton SJ, Colombo I. Particle Production of Steroid Drugs Using Supercritical Fluid Processing. Journal of Industrial \& Engineering Chemistry. 1996;35(12):4718-26.

51. Kunastitchai S, Pichert L, Sarisuta N, Muller BW. Application of aerosol solvent extraction system (ASES ) process for preparation of liposomes in a dry and reconstitutable form. International $\mathrm{J}$ of Pharmaceutics 2006;316:93-101.

52. Hanna M, York P, inventorMethod and apparatus for the formation of particles1994.

53. Naik S, Patel D, Surti N, Misra A. Preparation of PEGylated liposomes of docetaxel usinf supercritical fluid technology. J of Supercritical Fluids. 2010;54:110-9.

54. Varona S, Marin A, Cocero MJ. Liposomal incorporation of lavandin essential oil by thin-film hydration method and by Particles from GasSaturated Solution. Industrial \& Engineering Chemistry Research. 2011;50:2088-97.

55. Xia F, Hu D, Jin H, Zhao Y, Liang J. Preparation of lutein proliposome by supercritical anti-solvent technique. J of Food Hydrocolloids 2012a;26:45663.

56. Lesion L, Crampon C, Boutin O, Badens E. Preparation of liposomes using the supercritical anti-solvent (SAS) process and comparison with a conventional method. J of Supercritical Fluids. 2011c;57:162-74.

57. Xia F, Jin H, Zhao Y, Guo X. Supercritical antisolvent-based technology for preparation of vitamin D3 proliposomes and its characteristics. Chinese Journal of Chemical Engineering. 2011;19:1039-46.

58. Xia F, Jin H, Zhao Y, Guo X. Preparation of coenzyme Q10 liposomes using supercritical antisolvent technique. Journal of Microencapsulation. 2012b;29:21-9.

59. Liu G, Wang W, Wang H, Jiang Y. Preparation of 10-hyroxycamptothecin proliposomes by the supercritical carbon dioxide anti-solvent process. J of Chemical Engineering. 2014;243:289-96.
60. Graser F, Wickenhauser G, inventorProduction of fine particles from gas saturated solutions (PGSS)1982.

61. Charbitm G, Badens E, Boutin O. Methods of Particle Production. In Supercritical fluid technology for drug product development. York P, Kompella UB, Shekunov BY, editor: Informa healthcare; 2004. 159-212 p.

62. Bleich J, Müller BW, Wassmus W Aerosol solvent extraction system - a new microparticle production technique. International $\mathrm{J}$ of Pharmaceutics. 1993;97(1):111-7.

63. Jung J, Perrut M. Particle design using supercritical fluids: Literature and patent survey. $\mathrm{J}$ of Supercritical Fluids 2001;20:179-219.

64. Reverchorn E, Torino, E., Dowy, S., Braeuer, A., Leipertz, A. Interactions of phase equilibria, jet fluid dynmacis and mass transfer during supercritical antisolvent micronization. Chem Engineering Journal. 2010;156:446-58.

65. Bridson RH, Santos RCD, Al-Duri B, Mcallister SM, Robertson J. The preparation of liposomes using compressed carbon dioxide: strategies, important consideration and comparison with conventional techniques. $\mathrm{J}$ of Pharmcy \& Pharmacology. 2006;58:775-85.

66. Reverchorn E, Porta GD, Faliven MG. Process parameters and morphology in amoxicillin micro and submicro-particles generating by supercritical antisolvent precipitation. J of Supercritical Fluids. 2000;17:239-48.

67. Bleich J, Kleinebudde P, Müller BW. Influence of gas density and pressure on microparticles produced with the ASES process. International J of Pharmaceutics. 1994;106:77-84.

68. Müller HR, MaĖder K, Gohla S. Solid lipid nanoparticles (SLN) for controlled drug delivery \pm a review of the state of the art. European Journal of Pharmaceutics and Biopharmaceutics 2000;50:161-77.

69. Clavier J-Y, Perrut M. Chapter 15: Scale-Up Issues for Supercritical Fluid Processing in Compliance with GMP. 1 ed. P. York, U.B. Kompella, B.Y. Shekunov, editor. Lavipharm, East Windsor, New Jersey, U.S.A. and Separex 5, Champigneulles, France: Informa Healthcare; 2004.

70. Zhang W, Wang G, See E, Shaw JP, Baguley BC, Liu J, Amirapu S, Wu Z. Post-insertion of poloxamer 188 strengthened liposomal membrane and reduced drug irritancy and in vivo precipitation, superior to PEGylation. Journal of Controlled Release. 2015;203:161-9.

71. Karn P, Cho W, Park HEJ, Park SJ, Hwang SJ. Characterisation and stability studies of a novel liposomal cyclosporin A prepared using the supercritical fluid method: comparison with the modified conventional Bangham method. International J of Nanomedicine 2013;8:356-77. 
Table 4. Current research on preparation of proliposomes using various supercritical fluid technologies.

\begin{tabular}{|c|c|c|c|c|c|c|c|c|c|c|}
\hline $\begin{array}{l}\text { Method } \\
\text { used }\end{array}$ & $\begin{array}{l}\text { Temperature/ } \\
\text { pressure } \\
\left({ }^{\circ} \mathrm{C} / \text { bar }\right)\end{array}$ & Ingredients/Solvents & $\begin{array}{l}\text { Bioactive (drug } \\
\text { loading, } \% \mathrm{w} / \mathrm{v})\end{array}$ & $\begin{array}{l}\text { Solution } \\
\text { flow rate } \\
(\mathrm{mL} / \mathrm{h})\end{array}$ & $\begin{array}{l}\mathrm{CO}_{2} \\
\text { flow rate } \\
(\mathrm{g} / \mathrm{h})\end{array}$ & $\begin{array}{l}\text { Particle size } \\
\text { range }(\mu \mathrm{m}) \\
(\text { morphology })\end{array}$ & $\begin{array}{l}\text { Yield } \\
(\%)\end{array}$ & $\begin{array}{l}\text { Drug } \\
\text { Loading } \\
(\%)\end{array}$ & Year & Ref \\
\hline SAS/GAS & $\begin{array}{l}35 / \\
80-110\end{array}$ & $\begin{array}{l}\text { PC/phosphatarolamine } \\
2 \% \text { ethanol }\end{array}$ & API/drug free & $10-28$ & 400 & $\begin{array}{l}1-40 \\
\text { (spherical) }\end{array}$ & NR & NA & 2000 & (38) \\
\hline ASES & $\begin{array}{l}31-60 / \\
85-105\end{array}$ & $\begin{array}{l}\text { PC/chol/poloxamer } 407 \\
\text { methylene chloride }\end{array}$ & $\begin{array}{l}\text { miconazole } \\
(19 \& 38)\end{array}$ & 180 & 6000 & $\begin{array}{l}2.7-16.2 \\
\text { (cubic/rod-like) }\end{array}$ & $50-70$ & NR & 2006 & (51) \\
\hline $\begin{array}{l}\text { ASES/T-piece } \\
\text { assembly }\end{array}$ & $\begin{array}{l}20-55 / \\
150-250\end{array}$ & $\begin{array}{l}\mathrm{PC} / \mathrm{DMPC} / \mathrm{DPC} / \\
\mathrm{Chol} / 7 \% \text { ethanol }\end{array}$ & API/drug free & $15-30$ & $\begin{array}{l}540- \\
2580\end{array}$ & $\begin{array}{l}1-3 \text { (cubic/ } \\
\text { acicular) }\end{array}$ & NR & NA & 2006 & (52) \\
\hline SAS & $\begin{array}{l}34-46 / \\
100-220\end{array}$ & $\begin{array}{l}\text { hydrogenated PC/ } \\
\text { DGPE/Chol/PEG2000/ } \\
\text { chloroform:methanol, 2:1 }\end{array}$ & docetaxel & 9 & $1800-7200$ & $\begin{array}{l}0.27 \pm 0.003 \\
(\mathrm{NR})\end{array}$ & $\begin{array}{l}37.5 \\
\pm 4.5\end{array}$ & $23.6-67.5$ & 2010 & (53) \\
\hline PGSS & $\begin{array}{l}20-120 / \\
10-120\end{array}$ & $\begin{array}{l}\text { soybean lecithin } \\
\text { (97\% phospholipids)/ } \\
\text { Chol/chloroform }\end{array}$ & lavandin & NA & 15000 & $1.4-24.8$ & NR & $\begin{array}{l}2.7-14.5 \\
\text { liposome }\end{array}$ & 2011 & (54) \\
\hline SEDS & $\begin{array}{l}35-55 / \\
80-120\end{array}$ & $\begin{array}{l}\text { hydrogenated PC/ } \\
\text { ethanol }\end{array}$ & vitamin $D_{3}$ & 30 & 6000 & $\begin{array}{l}0.3-0.6 \\
\text { (irregular spheres) }\end{array}$ & NR & $\begin{array}{l}3.62- \\
12.89\end{array}$ & 2011 & (55) \\
\hline SEDS & $\begin{array}{l}35-50 \\
80-160\end{array}$ & $\begin{array}{l}\text { hydrogenated PC/ } \\
\text { ethanol:dichloromethane }\end{array}$ & $\begin{array}{l}\text { Lutein } \\
(0.73)\end{array}$ & $30-90$ & 1800 & $\begin{array}{l}0.2 \\
\text { (spherical) }\end{array}$ & NR & 55.5 & 2012 & (57) \\
\hline SEDS & $\begin{array}{l}35-55 \\
80-160\end{array}$ & $\begin{array}{l}\mathrm{PC} / \mathrm{Chol} / \\
\text { ethanol:dichloromethane }\end{array}$ & $\begin{array}{l}\text { coenzyme Q10 } \\
(1.8)\end{array}$ & 60 & $1.7 \mathrm{~m}^{3} / \mathrm{h}$ & NR & NR & 8.9 & 2012 & (58) \\
\hline PGSS & $\begin{array}{l}102-123 / \\
81-102\end{array}$ & $\begin{array}{l}\text { Soybean lecithin/ } \\
\text { dichloromethane }\end{array}$ & $\begin{array}{l}\text { beta-carotene } \\
(6.2-7.2)\end{array}$ & NA & 1500 & $10-500$ & $\begin{array}{l}19.2- \\
44.9\end{array}$ & $\begin{array}{l}34.4- \\
58.7\end{array}$ & 2012 & (9) \\
\hline GAS & $\begin{array}{l}35-50 / \\
80-250\end{array}$ & $\begin{array}{l}\text { egg PC/lactose anhydrous/ } \\
\text { ethanol }\end{array}$ & $\begin{array}{l}\text { cyclosporin A } \\
\text { (2) }\end{array}$ & NR & NR & $0.97-1.53$ & $\begin{array}{l}42.2- \\
89.3\end{array}$ & $\begin{array}{l}9.4- \\
20.5\end{array}$ & 2013 & (8) \\
\hline SAS & $\begin{array}{l}30-50 / \\
80-160\end{array}$ & $\begin{array}{l}\text { soy lecithin/cholesterol/ } \\
\text { dimethyl sulfoxide }\end{array}$ & $\begin{array}{l}\text { 10-hydroxy } \\
\text { camptothecin }\end{array}$ & $18-90$ & 1200 & $0.21 \pm 0.04$ & NR & 5.33 & 2014 & (59) \\
\hline
\end{tabular}

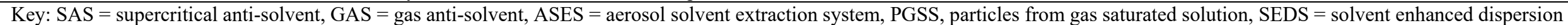

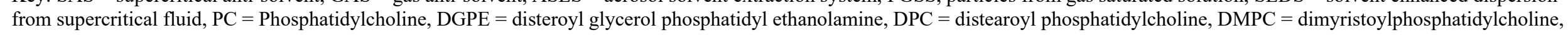
Chol $=$ cholesterol, $\mathrm{NA}=$ not applicable, $\mathrm{NR}=$ not recorded . 
J Pharm Pharm Sci (www.cspsCanada.org) 18(5) 747 - 764, 2015

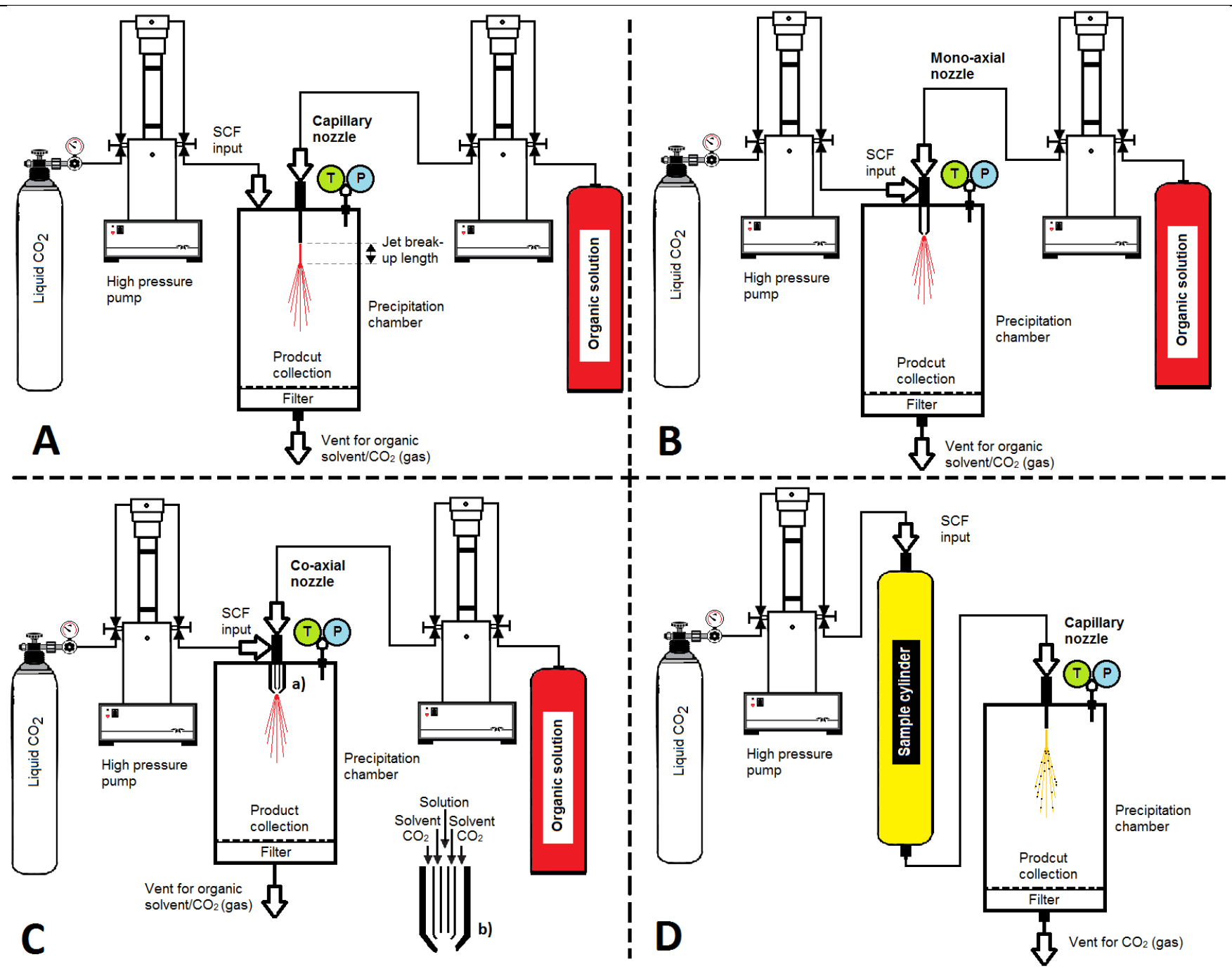

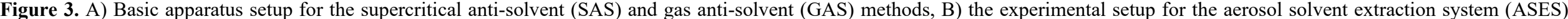

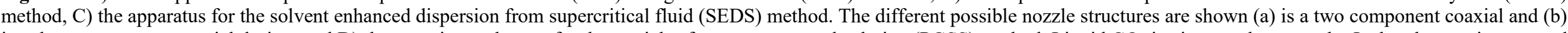

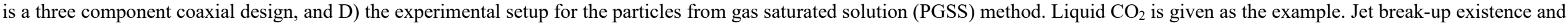
lengths are for conceptual aid only. 
J Pharm Pharm Sci (www.cspsCanada.org) 18(5) 747 - 764, 2015 